\title{
UNIONIZATION AND UNEMPLOYMENT RATES: A RE-EXAMINATION OF OLSON'S LABOR CARTELIZATION HYPOTHESIS
}

\author{
William C. Gruben and Keith R. Phillips*
}

\begin{abstract}
This paper presents a test of Mancur Olson's theory of the role that labor cartelization plays in determining interregional variations in unemployment rates. In Olson's theory, the regional degree of labor cartelization contributes to interregional variations in unemployment rates. We show that Olson's theory may be validated in the context of an empirical model that accommodates not only his theory, but also a competing hypothesis due to Freeman and Medoff, as well as business-cycle and sectoral shiftrelated explanations of interregional variations in unemployment rates. Nevertheless, our results also offer partial substantiation of the Freeman and Medoff hypothesis. According to Freeman and Medoff, the positive relation between variation in degrees of unionization and unemployment rates among geographic regions may reflect the concentration of unions in "older industrial parts of the economy."

In this paper, we present a test of Mancur Olson's (1986) theory of the role that labor cartelization plays in determining interregional variations in unemployment rates. We show that Olson's theory may be validated in the context of an empirical model that accommodates not only his theory, but also a competing hypothesis due to Richard Freeman and James Medoff (1984), as well as businesscycle and sectoral shift-related explanations of interregional variations in unemployment rates. Nevertheless, our results also offer partial substantiation of the Freeman and Medoff hypothesis. Furthermore, our results suggesta less significant role for unions in explaining interregional variations in unemployment than what is derived from Olson's own empirical model.
\end{abstract}

'Senior EconomistFederal Reserve Bank of Dallas, and Economist Federal Reserve Bank of Dallas, respectively. We wish to thank the attendees of the University of Maryland Macroeconomics Workshop, as well as those at the session on the political economy of regional growth at the 1989 meetings of the Southern Regional Science Association in Chapel Hill, North Carolina for their helpful comments on this paper. All errors and omissions, of course, are our responsibility. Contents of this document do not reflect official positions of the Federal Reserve Bank of Dallas or of the Federal Reserve System.
In Olson's theory, the regional degree of labor cartelization contributes to interregional variations in unemployment rates because unions restrict the supply of workers to an industry in order to extract supracompetitive wages. ${ }^{1}$ Since union wages are held above the rates that would obtain under perfectly competitive assumptions, firms in industries in heavily-unionized areas hire fewer workers than they would in the absence of unions. ${ }^{2}$ The high wages induce workers to queue up for union jobs, but many never get them. ${ }^{3}$ Where there is some degree of geographic labor immobility, unemployment rates tend to remain higher in areas where there is a high degree of unionization, even in the presence of some migration from high-wage/heavily unionized areas to low wage/nonunionized areas. Indeed, Olson argues that his paradigm explains why there has been net migration from the Northeast to the South and Southwest, despite relatively high wages in the Northeast. Since people prefer high wages to low, the movement from high-wage regions to low-wage regions signifies that there was "unemployment and disequilibrium in the high wage regions" $\left(1986\right.$, p. 282). ${ }^{4}$

Olson expresses his theory, in part, by detailing a simple empirical model that is designed to consider these phenomena. He finds that interregional variations in unemployment rates may be explained, in part, by variations in the degree of unionization, as well as by regional differences in industrial composition.

In a competing analysis of the relationship between unionization and unemployment, Freeman and Medoff also note that there is a positive correlation between the percentage of the workforce that is unionized in a geographic area and the rate of unemployment. Unlike Olson, however, they argue that this statistical relationship may simply reflect union concentration in "older industrial parts of the economy" (1984, p. 120).

Freeman and Medoff's notion, that the correlations between unionization and unemployment rates may simply reflect the correlation of both variables with the predominance of older and less profitable plants, is consistent with the following argument. Plants in the older, industrialized portions of the country are less efficient than plants elsewhere. As a result, rates of return to capital are relatively low in such areas. Accordingly, plants in these older areas are likely to be among the first closed during an economic downswing and the last opened during an up- 
swing. Where there is some degree of geographic labor immobility, then unemployment rates will remain higher on average over time in areas where rates of return to plants are low. If unionization happens to be higher in regions with older plants that are less efficient and have lower rates of profitability, then an examination of the relations between unionization and unemployment without also considering some measure of plant efficiency may suffer from specification error.

Although neither Olson nor Freeman and Medoff use empirical models to test their competing arguments, some by-products of an empirical model presented by Charles Hulten and Robert Schwab (1984) facilitate such a test. As part of an examination of the determinants of interregional variations in productivity growth, Hulten and Schwab estimate rates of return to manufacturing plant and equipment for each of the nine census divisions of the United States. These data offer a picture of the older industrial areas that is largely consistent with the implications the areas have for Freeman and Medoff. That is, average rates of return to manufacturing capital in the Snow Belt areas of the United States are below the national average for all but three years of the period 1955-1978. Hulten and Schwab's Snow Belt, which includes the New England, Middle Atlantic, East North Central and West North Central census divisions, is coterminous with what they describe as "older regions of the United States" (1984, p. 152). It is also coterminous with the more heavily unionized areas of the country.

\section{Interregional Unemployment Rate Variations in a Broader Theoretical Context}

Although we use Hulten and Schwab's data as part of a test of Freeman and Medoff's and Olson's paradigms, these tests are included as only a portion of a more comprehensive model. This model also accommodates two broader principles commonly perceived to be at work in generating interregional variations in unemployment rates. It is to these two broader principles, cyclical variations and sectoral shifts, that we now turn.

The traditional cyclical approach to explaining interregional variations in unemployment rates emphasizes the role of aggregate fluctuations upon individual regions. In this paradigm, developed by Brechling (1967) and subsequently applied by F. Lazar (1977), Lynn Browne (1978), L.J. King and G.L. Clark (1978) and Thomas Hyclak and Gerald Lynch (1980), aggregate fluctuations impact on different regions in accordance with the relative importance of various industries in those regions. That is, owing to the non-neutral effect across industries of the business cycle (Wesley Mitchell, 1941) theregional dispersion of unemployment rates is seen as the detailed impact of this aggregate cyclical activity.

Our model also accommodates the sectoral shift theory. This theory has precursors (Edmund Phelps, et. al., 1970; Robert Lucas and Edward Prescott, 1974), but its foundations are largely due to David Lilien (1982). According to this theory, shifts in relative labor demands among sectors of the economy necessitate a sectoral reallocation of the labor force. When information and labor mobility are costly, these sectoral shifts lead to fluctuations in the natural rate of unemployment that are independent of traditional aggregate demand-generated effects on unemployment. Thus, when changes are occurring in relative labor demands across industries, the unemployment rate can rise even if the economy is growing.

More recently, the foregoing sectoral shift explanations have been refined and extended to the empirical examination of regions. In these models (George Neumann and Robert Topel, 1984 and William Gruben and Keith Phillips 1986) permanent sectoral shifts in labor demand may lead to temporary changes in the natural rate of unemployment within a region, even in the absence of what are traditionally considered as business cycle-linked fluctuations. The distinction between permanent and transitory shifts is important. Only the permanent components of sectoral shifts in labor demand imply a reallocation of workers among sectors. A transitory shift may only describe events tied to the non-neutrality of the business cycle. In the case of a transitory shift, workers who are laid off during a business cycle downturn may be rehired during the upswing. A permanent shift implies that certain jobs are gone forever.

In the model presented below, we attempt to capture all of the explanations of interregional variations in unemployment rates that are described in the two preceding sections. That all of these considerations are accommodated is important because they demonstrate that Olson's claims can be validated in the context of a more fullyspecified model than those previously presented in evaluations of his theory.

\section{A Model of Interregional Variations in Unemployment Rates}

Interregional variations in unemployment rates are characterized here as determined by the following demand considerations.

$$
u_{i t}=u_{i}\left[C_{t}, S_{t}, I_{i t}, R_{i t}, \pi_{i t}, U_{i t}\right]
$$

where $u_{i t}$ is the unemployment rate in region $i$ at time $t, C_{t}$ represents national business cycle behavior at time $t$, and $S_{t}$ 
characterizes permanent national sectoral shifts in the demand for labor. $I_{\text {it }}$ represents industrial structure in region $i$ at time $L . R_{i t}$ expresses the nature of correlation between the composition of employment in region $i$ at time $t$ and permanent shifts in the national distribution of employment demand. $\pi_{\mathrm{it}}$ is the relative rate of returns to manufacturing capital in region $i$ at time $t$ compared with the national rate, and $\mathrm{U}_{\mathrm{it}}$ is the degree of unionization in region $\mathrm{i}$ at $\mathrm{t}$.

Thus, in this model, variations in unemployment rates over time are determined by national business cycle fluctuations $\left(\mathrm{C}_{\mathrm{t}}\right)$ and by national permanent sectoral shifts $\left(S_{\text {r) }}\right.$. But other, specifically regional factors also have important influences.

The industrial structure $\left(I_{i 1}\right)$ of a region determines the impact of business cycle fluctuations on its unemployment rate because of the non-neutral effects across industries of the business cycle (Mitchell, 1941). Furthermore, while a permanent sectoral shift has important national effects, these are attenuated or aggravated at the regional level by the relative local concentration of industries that "win" or "lose" $\left(\mathbf{R}_{\mathrm{i}}\right)$ as part of this national industrial reorganization.

In a way that is consistent with Freeman and Medoff's argument, a vector of relative rates of return to capital among regions $\left(\pi_{i}\right)$ determines which area's plants are closed first during a cyclical downswing and which are opened last during the upswing. In regions with low rates of return on capital, the duration of unemployment will be longer than in regions with high rates of return. Finally, the degree of unionization $\left(\mathrm{U}_{\mathrm{i}}\right)$ affects interregional variations in unemployment rates in the manner described by Olson.

\section{Empirical Specification of the Model}

In order to test for the significance of these phenomena in explaining interregional variations in unemployment, we used a pooled time-series and cross-section model of the nine U.S. census regions and employed quarterly data for the period 1965-78. Observations conclude with 1978 because that is the last year for which Hulten and Schwab (1984) provide estimates and because the Annual Survey of Manufacturers data on which those estimates are based are unavailable in a continuous time series thereafter. We regressed seasonally adjusted unemployment rates on variables designed to capture each of the six arguments outlined above. The variables employed and the expected signs of their coefficients are described below.

\section{Aggregate Fluctuations and Sectoral Shocks}

As a measure of national aggregate fluctuations $\left(\mathrm{C}_{\mathrm{i}}\right)$ we use the standard Tatom and Rasch measure of GNP Gap. The farther actual GNP falls below the Tatom and
Rasch measure of potential GNP, the larger is the GNP gap. Following the normal convention (see Hyclak and Lynch, 1980 , for example), we use this variable contemporaneously (GAP) and with a one-quarter lag (LGAP). In this model, a positive relationship is expected between each of the two gap variables and a region's unemployment rate.

In order to capture the role of national permanent shifts $\left(\mathbf{S}_{1}\right)$ in the sectoral distribution of labor in explaining variations in unemployment rates, we rely on a computational procedure developed by Neumann and Topel (1984) and subsequently applied by Gruben and Phillips (1986) and by Ellen Rissman (1987). This procedure measures the absolute values of permanent shifts. Absolute values are important because, according to the theory of sectoral shifts, the rate of increase in the natural rate of unemployment is determined by the magnitude of sectoral labor demand redistribution and not by the direction of redistribution.

Recall that a distinction must be made between permanent and transitory sectoral shifts. Only the permanent components of sectoral shifts imply a reallocation of workers among sectors. A transitory shift may simply describe events linked to the non-neutrality of the business cycle. The procedure developed by Neumann and Topel, and described in Appendix A, uses changes in Euclidean lengths to characterize sectoral shifts in the demand for workers and it separates permanent from transitory components of these shifts. In reports of test results for the model, the national permanent shift variable we use is denoted as SHIFTN. Since a high (low) value for SHIFTN signifies a large (small) permanent redistribution of labor demand, changes in SHIFTN are expected to be positively related to changes in unemployment rates.

\section{Regional Arguments}

To characterize the impact of differences in regional industrial structures $\left(I_{i t}\right)$ upon differences in regional unemployment rates, we rely on a measure of employment portfolio variance similar to Michael Conroy's (1974). Conroy's procedure incorporates variance and covariance by industry in regional labor demand and it has several important implications in this role. Above all, it is a useful measure of the demand risk for labor.s To consider what variance and covariance in a regional labor market mean for demand risk, suppose that workers within a given region are mobile across industries. The non-neutrality of the business cycle suggests two effects pertinent to a given region with a given distribution of employment across industries. First, assume that one set of unrelated industries tends to experience greater labor demand variance, due to aggregate shocks, than some other set of unrelated industries. A region composed entirely of the first type of 
industries will face greater labor demand risk, and an accordingly higher average unemployment rate, than a region comprised solely of industries in the second group. This is the effect of variance.

Second, where labor requirements by each industry rise and fall together, covariance of demand also explains fluctuations in the demand for labor. With high covariance in a region, a worker who loses his job in one industry will have trouble finding work in the others because they, too, are likely to be caught in a downturn. We apply the general approach used by Conroy (1974), and described in Appendix $B$, to condense labor demand variance and covariance into a single variable, VARCOV. We expect VARCOV to be positively related to unemployment rates.

To consider the role of local "winning" and "losing" industries in attenuating or aggravating the local effects of a national permanent sectoral shift in labor demand $\left(\mathbf{R}_{\mathrm{it}}\right)$, recall that a significant national shift would cause the average level of unemployment to rise across all regions of the nation. Whether a particular region's unemployment rate will rise, however, depends on the relation between that region's composition of employment and the characteristics of the national permanent shift. Suppose a region is relatively well-endowed with sectors whose national labor shares are undergoing a permanent positive (negative) shift. The effect of such a national shift on these local "winning" ("losing") industries may actually result in a drop (aggravate the rise) in the region's unemployment rate. The regional shift variable, SHIFTR, captures this effect. $^{6}$

This is not to say that national sectoral reallocations of labor demand cannot result in any unemployment in a region dominated by sectors that are growing nationally. For example, national demand shifts may affect the supply of labor to the region by inducing migration. We simply argue that regional industrial composition may, under some circumstances, partially or wholly offset the disruption caused by such a national shock. Thus, the expected sign of the coefficient on SHIFTR would be negative.

We attempt to consider Freeman and Medoff's argument, that high unemployment rates in heavily unionized areas may be related to the concentration of union activity in older industrial areas, through the use of a profit measure $\left(\pi_{\mathrm{i}}\right)$. If the real cause of higher unemployment rates in such areas is the relatively low profitability of capital there, and is not unionization, then a variable that captures relative regional rates of return to manufacturing capital should prove significant in our empirical model while a variable that captures a pure unionization effect ought to be insignificant. To capture the impact of differences in returns to manufacturing capital, we use Hulten and Schwab's measure of absolute rate of return for each region, divided by their estimated national average rate of return. This procedure for estimating relative rates of return follows Robert Engle (1974). If all regions' absolute rates of retum change proportionally, our measure doesnot change for any region. These are annual rates of return, unlike our other data which are quarterly. We denote this characterization of relative rates of return as RELPROF. We expect the coefficient on RELPROF to be negative. As relative profit rates go up, caeteris paribus, unemployment rates fall.

Finally, in order to test the strength of Olson's hypothesis against that of Freeman and Medoff, we include a variable to capture the strength of unionization $\left(U_{i t}\right)$. Specifically, we include the percentage of a region's nonagricultural employees who are union members, called UNION. We expectapositive relationship between UNION and a region's rate of unemployment.

\section{Estimation Of The Model}

We performed generalized least squares pooled crosssection and time series regressions on quarterly unemployment rates for each of the nine U.S. census divisions for the observation period 1965-78. Corrections were made for both heteroskedasticity and autocorrelation.? The test statistics of alternative regressions are presented in Table One.

The model demonstrates that both national aggregate fluctuations (GAP andLGAP) and national sectoral shocks (SHIFTN)are positively linked to variations in unemployment rates over time. The variance and covariance of employment demand by industry (VARCOV) explains a significant portion of interregional variation in unemployment rates. Furthermore, the results demonstrate that the impacts of national sectoral shocks are attenuated or aggravated by the relative importance of "winning" or "losing" industries in a region's industrial structure (SHIFTR).

While these results offer gratifying confirmations of some of our hypotheses, the focus of this paper is upon the role of unions (UNION) and of relative rates of return to capital (RELPROF). These two variables were included to explain fluctuations in unemployment rates in accordance with Olson's and Freeman and Medoff's paradigms, respectively. As Table One demonstrates, the variables relevant to each paradigm take on the expected signs well within the .05 level of significance.

The table also shows that, while the increase in the explanatory power of regression equations containing either or both of these variables is noticeable, it is not great. This result should not be surprising, considering the importance that variables such as GAP, LGAP, and SHIFTN have been shown to have in explaining regional unemployment rate variations in other models (Hyclak and Lynch, 1980; Neumann and Topel, 1984; Gruben and Phillips, 1986). 
Table One

Pooled Time Series and Cross Section Census Division Employment Regression 1965-1978 1

\begin{tabular}{lcccc}
\hline Variable & $(1)$ & $(2)$ & $(3)$ & $(4)$ \\
\hline Constant & -2.9653 & -00.78196 & -00.1044 & -1.8291 \\
& $(-2.5603)$ & $(-0.80425)$ & $(-0.13107)$ & $(-1.8070)$ \\
GAP & 00.07615 & 00.08538 & 00.10362 & 00.07943 \\
& $(02.3531)$ & $(02.5949)$ & $(3.1026)$ & $(2.4225)$ \\
LGAP & 00.1117 & 00.11644 & 00.12455 & 00.11155 \\
& $(4.0900)$ & $(4.1956)$ & $(4.4170)$ & $(4.0298)$ \\
VARCOV & $14.646 \mathrm{E}+02$ & $11.027 \mathrm{E}+02$ & $8.9949 \mathrm{E}+02$ & $11.623 \mathrm{E}+02$ \\
& $(6.9866)$ & $(6.0690)$ & $(5.7689)$ & $(6.2390)$ \\
SHIFTN & 65.016 & 63.976 & 50.510 & $(3.060$ \\
& $(4.3876)$ & $(4.2410)$ & $(3.3114)$ & -372.68 \\
SHIFTR & -380.80 & -398.12 & -342.57 & $(-6.9952)$ \\
& $(-6.3069)$ & $(-6.5697)$ & $(-6.2860)$ & \\
RELPROF & -00.6443 & -00.60514 & & $00.1143 \mathrm{E}-01$ \\
& $(-2.8794)$ & $(-2.6994)$ & & $(2.3417)$ \\
UNION & $00.1781 \mathrm{E}-01$ & & & .5196 \\
& $(4.1822)$ & & .4791 & .5138 \\
$\mathrm{R}^{2}$ & .5602 & .5135 & .4739 & 497 \\
$\bar{R}^{2}$ & .5540 & .5076 & 498 & \\
& & & & \\
d.f. & 496 & 497 & & \\
\hline \hline
\end{tabular}

$1_{\text {t-statistics in parentheses. }}$

It is interesting also to note the robustness of the test statistics for RELPROF to the inclusion of UNION, and vice versa, in the regression equations. The increase in explanatory power that UNION contributes to a regression equation is about the same when RELPROF is not in the equation as when RELPROF is included. Adding UNION to an equation that does not contain RELPROF increases the $R^{2}$ by about .04 . Entering UNION in an equation that already includes RELPROF increases the $R^{2}$ by about .05 . Inserting RELPROF in an equation that does not contain UNION raises the $R^{2}$ by about .03. Inserting RELPROF in an equation that already contains UNION raises the $R^{2}$ by about .04.

Furthermore, the coefficient values and levels of significance for RELPROF are little affected by the presence or absence of UNION in the equation. When UNION is placed in an equation with RELPROF, however, both the coefficient value and the t-statistic for UNION increase. Nevertheless, even though Freeman and Medoff note that union concentration is heaviest in older industrial areas and Hulten and Schwab show that these areas also have rela- tively low rates of return to manufacturing capital, the phenomena that UNION and RELPROF capture seem to be sufficiently different so that multicollinearity does not appear to be a serious problem in the model. ${ }^{8}$

Another aspect of the model results that may be instructive is also related to the coefficient values for the UNION variable. Olson's (1986) empirical models are sufficiently different from ours that conclusions drawn from comparisons ought to be extremely tentative. In addition to using different time periods than we do, Olson's model considers a cross section of states. By comparison, because RELPROF is available only for census divisions, the model presented here does not use data that is disaggregated by state. Accordingly, Olson's model is capable of capturing more cross sectional variation than ours.

Nevertheless, it may be useful to see that the effect of unionization on unemployment rates is noticeably greater in Olson's model than in the results we present. Specifically, Olson's results show that "a 10 percent increase in the proportion of the nonagricultural labor force that is unionized (an increase from, say, 20 percent to 30 percent) 
would increase the unemployment rate by 1 percent (an increase from 8 percent to 9 percent unemployment)" (1986, p. 300).

The results of our empirical model that includes both RELPROF and UNION suggest that a similar 10 percentage point increase in the proportion of the nonagricultural labor force that is unionized would raise the unemployment rate by a little less than 0.2 percent, an increase from 8.0 percent to almost 8.2 percent. This relationship is not trivial. With a U.S. civilian labor force currently of about 120 million, an increase of 0.2 percentage point in the U.S. unemployment rate would signify an additional 240 thousand jobless workers. But if we ignore the sampling differences between our model and Olson's, this result suggests that a more fully specified model than Olson's may lead to estimates that imply a less seriously problematic role for unions in generating unemployment.

Having compared the implications of unionization for our empirical model with those for Olson's, we turn to a comparison of UNION with RELPROF. Following Engle's (1974) specification, RELPROF is a ratio, rather than a percentage. This is why the absolute value of the coefficient on RELPROF is so much larger than that of UNION. The value of RELPROF's coefficient is about -.6. If the ratio of a region's rate of return to that of the most profitable region falls from, say, .80 to .70 , an increase in the unemployment rate of about .06 is implied.

To extend this comparison, consider the elasticities at means for UNION and RELPROF. When both variables appear in the same equation, the elasticity for UNION is .0714 , and RELPROF's is -.0979 . The ratio of the absolute value of the elasticity of UNION to that of RELPROF is 0.73. A given percentage movement upward in the UNION variable has slightly less than three-fourths as great an effect on unemployment rates as a similar percentage decline in RELPROF.

\section{Concluding Remarks}

We have examined the competing hypotheses, due to Olson and to Freeman and Medoff that: (1) unionization explains a significant portion of interregional variations in unemployment rates (Olson, 1986). (2) the correlation between unionization and unemployment rates is simply an artifact of union concentration in older, less efficient industrial areas (Freeman and Medoff 1984). We tested these hypotheses empirically in a series of pooled time series and cross-sectional GLS regression equations, using the percentage of nonfarm employment that is unionized to proxy the unionization effect, and applying a measure of relative rates of return to manufacturing capital to capture the older-regions effect. We found that unionization explains a significant degree of unemployment variation, even after empirically accounting for the older-regions effect, and for aggregate cyclical fluctuations, sectoral shocks, and for regional differences in industrial structure. Nevertheless, a measure of the older-region effect also had unambiguously significant explanatory power for variations in unemployment rates across regions over time.

While our results verify Olson's hypothesis, they suggest that unionization plays a less important role in explaining unemployment than what is implied in Olson's empirical model. Although Freeman and Medoff's olderregions hypothesis does appear to explain some unemployment rate variation, our findings suggest that the correlation between unemployment rates and unionization is not spurious.

\section{Notes}

'The ability of unions to extract wage gains greater than what could be achieved in their absence has been an accepted notion in academic literature since the work of Gregg Lewis (1963) and continues to be the assumption on which research on the effects of unionization is based, as in Stephen Bronars and John Lott (1989).

${ }^{2}$ This argument is consistent with the findings of David Blanchflower, Neil Millward and Andrew Oswald (1989) that British unionized firms have slower rates of employment growth than nonunionized firms, even when account is taken of firm-size differentials between the former and the latter.

${ }^{3}$ Connections between unionization and unemployment have been suggested in the literature for some time. For example, Curtis Eaton and Philip Neher (1976) present a theoretical model in which workers are "voluntarily" unemployed while searching for jobs, attempting to arbitrage a wage gap created by partial unionization. Similarly, although their discussions are not directed to unionization, Harberger (1971) and Todaro (1969) note that workers in less developed countries often prefer to remain unemployed in urban areas in hopes of finding a job covered by minimum wage legislation, rather than to continue working in the uncovered rural sector.

"Note that, in Olson's paradigm, the positive relation between unionization and unemployment does not solely involve a theory of layoffs. Workers who cue up to find union jobs and, failing to get them, ultimately take other employment, need not be employed while engaged in search. That is, workers may choose to remain unemployed while seeking unionized jobs. This search unemployment is positively linked to the presence of some unionized employment, which pushes up the unemployed workers' reservation wages.

${ }^{5} \mathrm{~A}$ positive relationship exists between demand risk in a region and the region's unemployment rate. Lilien (1982) notes, for example, that fewer layoffs would occur in an economy where employment grew at +2 percent per year in all firms than in one where employment was growing at +8 percent per year in half of 
all firms and by -4 percent in the rest, even though both economies would have identical growth rates in aggregate employment.

${ }^{6} \mathrm{We}$ are indebted to John Kenton Hill for the development of this variable. Let $s_{i n}{ }^{P}$ represent the permanent component of a directional change in the national employment share of industry $i$ at time $t$, as discussed in Appendix A. Unlike what takes place in the Neumann and Topel (1984) procedure, this variable includes the sign of the movement in the employment share of an industry, and not simply the absolute magnitude of movement. Let $s_{i}$ represent the (five-year moving average) employment share-weight that an industry has in a given region and $s_{\mathrm{wi}}$ represent the weight the same industry has nationally. We characterize the interaction of the $\mathrm{De}_{\mathrm{in}}{ }^{\mathrm{P}} \mathrm{v}$ ariable (see Appendix A) with the local industrial structure by the following expression, which captures the interaction of directional changes in the industrial composition of U.S. employment with the industrial composition of a given region.

$$
\text { SHIFTR }=\sum_{i}\left[s_{\text {in }}-s_{\text {nit }}\right] \Delta e_{i}^{P}
$$

'Because the cross-sectional units are geographical regions with arbitrarily drawn boundaries, it is likely that they are not mutually independent and that heteroskedasticity may be present. Also, separate regressions, performed on each of the nine regions, showed a high degree of time-wise autocorrelation to be present in the residuals. Accordingly, we applied a method that corrects for error terms that are cross-sectionally correlated and time-wise autoregressive. Following this method, which is described in Jan Kmenta (1971, pp. 512-4), we first applied ordinary least squares procedures to estimate the nine autoregressive parameters. We then transformed the variables to estimate the time-wiseuncorrelated error terms, which are used to estimate the covariance of the error terms across regions. The procedure then applies Aitken's generalized least squares procedure to obtain asymptotically efficient estimators of the regression coefficients and of their variances.

The robustness of the test statistics for RELPROF to the inclusion of UNION, and vice versa, in the regression equations may, at first blush, seem inconsistent with the economic literature that links measures of expected rates of return to the firm with the presence of unionization. For example, Ruback and Zimmerman (1984) find a negative relation between equity values and the onset of unionization in a firm. The measure we use captures only rates of return on capital, and does not capture firm profitability. Both the model we present and separate calculations we performed of the coefficient of correlation between the two variables suggest that our measures of unionization and of returns to capital are not significantly correlated.

\section{Appendix A}

Neumann and Topel develop a permanent sectoral shift variable using Euclidean lengths. They begin by generating a variable $\Delta e$, which measures the direction of permanent change in the sectoral distribution of employment, as follows. In any quarter, let $e_{t}=\left(e_{1 t}, \ldots e_{n}\right)$ be a vector of employment shares across $\mathrm{n}$ industry groups. The direction of permanent change in this distribution is the vector

$$
\Delta \tilde{e}_{t}=\sum_{j=1}^{J} \beta_{j} e_{t+j}-\sum_{j=1}^{J} \beta_{j} e_{t-j} \text { where } \sum_{j=1}^{J} \beta_{j}=1
$$

so that $\Delta \tilde{\mathrm{e}}$ is the difference between moving averages of future and past vectors of employment shares at each $\mathrm{t}$. In practice $\mathrm{J}=$ 16 quarters with smoothly declining weights $\beta_{j}=(.9) j /(7.33)$.

Given the direction of permanent change in the sectoral distribution of employment, the actual difference between the current employment distribution and the comformable past distribution is defined as

$$
\Delta \mathrm{e}_{\mathrm{t}}=\mathrm{e}_{\mathrm{i}}-\sum_{\mathrm{j}=1}^{\mathrm{J}} \beta_{\mathrm{j}} \mathrm{e}_{\mathrm{t}-\mathrm{j}}
$$

This vector gives the direction of current change in the sectoral distribution of employment. The vector has permanent and transitory components, but only the permanent component implies a sectoral reallocation of workers. The permanent component in each period is defined as the period-specific leastsquares projection of $\Delta \mathrm{e}_{\mathrm{t}}$ onto the vector $\Delta \tilde{e}_{\mathrm{t}}$ that measures the direction of permanent change, that is, the part of $\Delta e_{1}$ that can be “explained" by $\Delta \tilde{\mathrm{e}}_{\mathrm{t}}$ :

$$
\Delta \mathrm{e}_{\mathrm{t}}^{\mathrm{p}}=\left[\left(\Delta \tilde{\mathrm{e}}_{\mathrm{t}} \Delta \mathrm{e}\right) /\left(\Delta \tilde{e}_{\mathrm{t}} \Delta \tilde{\mathrm{e}}_{\mathrm{t}}\right)\right] \Delta \tilde{\mathrm{e}}_{\mathrm{t}}
$$

The longer this vector, the greater the permanent sectoral change, so that the measure of the permanent shock to the distribution of employment is the Euclidean length of $\Delta \mathrm{e}^{\mathrm{p}}$ :

$$
\text { SHIFTN }=\left\|\Delta \mathrm{e}_{\mathrm{t}}^{\mathrm{t}}\right\|=\left(\Delta \tilde{\mathrm{e}}_{\mathrm{t}} \Delta \mathrm{q}\right) /\left(\Delta \tilde{\mathrm{e}}_{\mathrm{t}} \Delta \tilde{\mathrm{e}}_{\mathrm{t}}\right)^{1 / 2}
$$

\section{Appendix B}

We use a measure of employment portfolio variance that is designed to separate the pure industrial composition effects upon unemployment variations across regions from factors that might be linked to the "older region" effect. In order to avoid capturing the "older region" effect in this variable, we use a national variance covariance measure and then weight it by a measure of long run employment share for each census division. This means that we develop a separate portfolio variance measure for each region, but the measure only reflects regional differences in industrial composition. The measure does not capture regional peculiarities of variance and covariance that might be derived from other effects. The measure of portfolio variance for each census division also changes over time. The employment portfolio variance measure is developed as follows.

which can be expanded to

$$
\sigma_{p}=\Sigma_{i} \sum_{j} s_{i} s_{j} \sigma_{i j}
$$

$$
\sigma_{p}=\Sigma_{j} s_{j}^{2} \sigma_{j}^{2}+\Sigma_{i m-j-i n i} s_{j} \sigma_{i j}
$$

where $\sigma_{j}^{2}$ represents the employment variance of industry $j, \sigma_{i j}$ 
represents the covariance of employment between industry $i$ and industry $j_{\text {, and }} s_{i}$ and $s_{j}$ represent the respective long-term employment share-weights of industry $i$ and industry $j$. Thus, every industry contributes to the regional portfolio variance both through its variance and through its covariances with other industries.

We disaggregate employment by the ten single-digit standard industrial classifications for the United States and estimate a relative variance covariance matrix for the period 1956-1978, as the variance covariance matrix of the residuals of employment around a five-year-moving-average trend standardized with respect to the mean of each series. Thus, each element of the matrix includes a relative covariance of the following form.

$$
\bar{\sigma}_{i j}=[T-2]^{-1}\left[\bar{E}_{i} \bar{E}_{j}\right]^{-1} \sum\left(E_{i t}-\hat{E}_{i t}\right)\left(E_{j t}-\hat{E}_{j t}\right)
$$

Here $E_{i i}$ and $E_{i j}$ represent the observed levels of employment in industries $i$ and $j$, respectively, during quarter t. $E_{i}$ and $E_{j}$ represent the expected levels of employment in industries $i$ and $j$, for quarter $t$, given by a five-year moving average estimated for each industry. $\bar{E}_{i}$ and $\bar{E}_{j}$ represent the arithmetic means of the individual industry time series.

This matrix can be condensed to a variable, VARCOV, describing the employment variance for a given region by applying region-specific weights to the portfolio variance formula as noted in equation (B1) and substituting the $\sigma_{i j}$ in equation (B3) into equation (B1) in place of $\sigma_{\mathrm{ij}}$. The resulting $\sigma_{\mathrm{p}}$ provides a measure of employment variance for each geographic region based on the region's industrial composition (as reflected in the weights) but using a national matrix (for the components of $\sigma_{i j}$ ). As weights, we use five-year-moving averages of the relative proportions of quarterly employment in each of the ten single-digit S.I.C industries for each of the nine census divisions.

\section{References}

Blanchflower, David G., Neil Millward and Andrew J. Oswald, "Unionization and Employment Behavior," NBER Working Paper No. 3180, November 1989.

Brechling, Frank, "Trends and Cycles in British Regional Unemployment." Oxford Economic Papers, March 1967, 19, 1-21.

Bronars, Stephen G. and John R. Lott, Jr., "Why Do Workers Join Unions? The Importance of Rent Seeking." Economic Inquiry, April 1989, 28, 305-324.

Browne, Lynn E., "Regional Unemployment Rates - Why Are They So Different?" New England Economic Review, July/ August 1978, 5-26.

Conroy, Michael E., “Alternative Strategies for Regional Industrial Diversification.” Journal of Regional Science, April 1974, $14,31-46$.

Eaton, A. Curtis and Philip A. Neher, "Unemployment, Underemployment, and Optimal Job Search." Journal of Political Economy, April 1975, 83, 355-375.
Engle, Robert F., “A Disequilibrium Model of Regional Investment." Journal of Regional Science, December 1974, 14, 367-376.

Freeman, Richard and James Medoff, What Do Unions Do? New York: Basic Books, 1984.

Gruben, William C. and Keith R. Phillips, "Understanding the Texas Unemployment Rate." Federal Reserve Bank of Dallas Economic Review, November 1986, 17-30.

Harberger, Amold C., "On Measuring the Social Opportunity Cost of Labor," International Labor Review, June 1971, 103 , 559-579.

Hulten, Charles R. and Robert M. Schwab, “Regional Productivity Growth in U.S. Manufacturing: 1951-78." American Economic Review, March 1984, 74, 152-162.

Hyclak, Thomas and Gerald Lynch, "An Empirical Analysis of State Unemployment Rates in the 1970s." Joumal of Regional Science, August 1980, 20, 377-386.

Kahn, Lawrence M. andKimio Morimune, "Unions and Employment Stability: A Sequential Logit Approach." International Economic Review, February 1979, 20, 217-235.

King, L.J. and G.L. Clark, "Regional Unemployment Patterns and the Spatial Dimensions of Macro-Economic Policy: The Canadian Experience 1966-1977." Regional Studies, June 1978, 12, 283-296.

Kmenta, Jan. Elements of Econometrics. New York: The Macmillan Company, 1971.

Lazar, F., "Regional Unemployment Rate Disparities in Canada: Some Possible Explanations." The Canadian Joumal of Economics, February 1977, 10, 112-128.

Lewis, H. Gregg, Unionism and Relative Wages in the United States. Chicago: University of Chicago Press, 1963.

Lilien, David M., "Sectoral Shifts and Cyclical Unemployment." Journal of Political Economy, August 1982, 90, 777-793.

Lucas, Robert E. Jr. and Edward Prescott, "Equilibrium Search and Unemployment." Journal of Economic Theory, February 1974, 7, 188-209.

Mitchell, Wesley C., Business Cycles and Their Causes. Berkeley, CA: University of Califomia Press, 1941.

Montgomery, Edward, "Employment and Unemployment Effects of Unions," January 1986, Unpublished paper.

Moore, Geoffrey H., Business Cycles. Inflation, and Forecasting. National Bureau of Economic Research Studies in Business Cycles No. 24. Cambridge, MA: Ballinger Publishing Company, 1980.

Neumann, George R. and Robert H. Topel, "Employment Risk, Sectoral Shifts and Unemployment." October 1984, Unpublished paper, forthcoming Quarterly Joumal of Economics.

Olson, Mancur, "Maintaining A Healthy Business Climate: A Broader Perspective on The Rates of Economic Growth and Of Unemployment in the Southern and Southwestern States," in Energy and the Southwest Economy: Proceed- 
ings of the 1985 Conference on Energy and the Southwest Economy. Dallas: Federal Reserve Bank of Dallas, 1986. Olson, Mancur, The Rise and Decline of Nations. New Haven: Yale University Press, 1982.

Olson, Mancur, The Logic of Collective Action. Cambridge, MA: Harvard University Press, 1965.

Phelps, Edmund, et al., Microeconomic Foundation of Employment and Inflation Theory. New York: Norton, 1970.
Rissman, Ellen R., "Wage Growth and Sectoral Shifts: New Evidence on the Stability of the Phillips Curve." Federal Reserve Bank of Chicago Staff Memorandum SM-87-1, 1987.

Todaro, Michael P., “A Model of Labor Migration and Urban Unemployment in Less Developed Countries," American Economic Review, March 1969, 59, 138-148. 